\title{
Oxygen Atom Transfer Energetics: Assessment of the Effect of Method and Solvent
}

\author{
Adriana Dinescu, Clinton Whiteley, Rachel R. Combs, and Thomas R. Cundari* \\ Center for Advanced Scientific Computing and Modeling, Department of Chemistry, University of North Texas, \\ Denton, Texas 76203
}

Received: September 7, 2005; In Final Form: January 25, 2006

\begin{abstract}
Several density functional methods, the semiempirical methods AM1 and PM3, Hartree-Fock, and Gaussian3 theories were applied to compute the oxygen atom transfer enthalpies for $14 \mathrm{X} / \mathrm{XO}$ couples (inorganic and organic systems, charged and neutral species, light and heavy main group element containing molecules). The calculated reaction enthalpies were compared to available experimental data. The G3 method alone was found to perform within the experimental error, while the popular B3LYP and BLYP functionals provided inadequate results. Solvent effects were estimated for 19 neutral and anionic X/XO couples by using the conductor-like polarizable continuum model and several cavity models coupled with the B3LYP/6-31++G$(2 \mathrm{~d}, 2 \mathrm{p})$ level of theory. Surprisingly, the magnitude of the aqueous solvent correction was found to vary significantly for different solute cavity models, occasionally giving larger errors than the gas-phase calculation.
\end{abstract}

\section{Introduction}

Many important industrial and biological reactions that are catalyzed by metalloenzymes ${ }^{1}$ (cytochrome P450, methane monooxygenase) and transition metal complexes ${ }^{2,3}$ involve the transfer of an oxygen atom to an organic substrate. Holm and co-workers have published an extensive experimental analysis of metal-centered oxygen atom transfer (OAT) reactions and numerous examples of the applications of different oxygen donors and acceptors. ${ }^{4,5}$ Modeling of OAT reactions is a complex process that requires, among other elements, accurate prediction of thermochemical data. In many cases, the desired oxidant is molecular oxygen. The most straightforward type of oxygen transfer reaction can be thermodynamically modeled in the gas phase involving only the reactant, molecular oxygen, and product (eq 1), in which $\mathrm{X} / \mathrm{XO}$ is a generalized oxygen atom acceptor/donor couple.

$$
\mathrm{X}+{ }^{1} /{ }_{2} \mathrm{O}_{2} \rightarrow \mathrm{XO}
$$

Computational chemistry has developed remarkably during the past decade due to the advent of methodology improvements such as density functional theory $\left(\mathrm{DFT}^{6}\right)$, Gaussian- $n$ theories, ${ }^{7-10}$ and coupled clusters methods. ${ }^{11}$ While the latter two are known for delivering chemical accuracy, their prohibitive costs most often give preference to the less computationally expensive DFT methods. The large number of published articles ${ }^{12}$ that employ the corrected-gradient density functionals demonstrates the power of DFT methods, but their accuracy in terms of predicting thermochemistry has been less studied in a methodical fashion for a diverse array of compounds, particularly inorganic compounds.

It is well-known that calculated reaction enthalpies depend on the choice of the exchange-correlation functional and basis set. The $\mathrm{B} 3 \mathrm{LYP}^{13,14}$ hybrid functional associated with a large basis set $(6-311+\mathrm{G}(3 \mathrm{df}, 2 \mathrm{p}))$ was found to perform reasonably well 15 (average absolute error $=3.11 \mathrm{kcal} / \mathrm{mol}$ ) on the "G2 neutral test set", which included 148 molecules (from the first

* Address correspondence to this author. E-mail: tomc@unt.edu. and second row main group elements). Since the usage of a large basis set becomes computationally demanding when applied to large molecules, we have in the present research investigated the accuracy of different functionals in conjunction with two popular compact basis sets: 6-31G(d) and cc-pVTZ. In this study we wish to ascertain whether one may employ DFT methods and compact basis sets to obtain comparably accurate calculated enthalpies on larger systems for which calculations with higher level methods or very large basis sets are not presently practical. We present here an analysis of the calculated reaction enthalpies at $298.15 \mathrm{~K}$ for a number of oxygen transfer reactions using several (pure and hybrid) functionals, Gaussian-3 (G3 $\left.{ }^{10}\right)$ theory, Hartree-Fock $\left(\mathrm{HF}^{16}\right)$, as well as semiempirical (AM1 ${ }^{17}$ and $\mathrm{PM} 3^{18}$ ) methods. We selected a set of reactions that includes inorganic and organic systems for which the enthalpies or free energies of reaction have been experimentally determined. The systems studied incorporated both gas and aqueous systems to estimate the importance solvent effects, as many important oxidants must operate in an aqueous environment. Finally, hybrid approaches to the modeling of the largest, and most experimentally relevant OAT systems are studied.

\section{Computational Methods}

All calculations were carried out utilizing the $\operatorname{Titan}^{19}$ and Gaussian98/Gaussian03 ${ }^{20}$ packages. Four density functionals were tested in this study: B3LYP (Becke's three-parameter hybrid functional ${ }^{13}$ using the LYP correlation functional containing both local and nonlocal terms of Lee, Yang, and Parr ${ }^{14}$ ), SVWN (Slater local exchange functional ${ }^{21}$ plus local correlation functional of Vosko, Wilk, and Nusair ${ }^{22}$ ), BLYP (Becke's 1988 exchange functional, ${ }^{23}$ which includes the Slater exchange along with the gradient correction, plus LYP correlation functional), and BP86 (Becke's 1988 exchange functional plus Perdew's 1986 correlation functional ${ }^{24}$ ). The other methods employed included the semiempirical AM1 and PM3, HF, and G3 methods. All systems were fully optimized at the abovementioned levels of theory and analytic calculations of the energy Hessian were performed to obtain the enthalpies and 
TABLE 1: Calculated (G3 method) and Experimental Reaction Enthalpies for the Reaction $\mathrm{X}+1 /{ }_{2} \mathrm{O}_{2}=\mathrm{XO}$

\begin{tabular}{|c|c|c|c|}
\hline \multirow[b]{2}{*}{$\mathrm{X} / \mathrm{XO}$} & \multicolumn{2}{|c|}{$\Delta H_{\mathrm{OAT}}(\mathrm{kcal} / \mathrm{mol})$} & \multirow{2}{*}{$\begin{array}{l}\text { unsigned error } \\
(\mathrm{kcal} / \mathrm{mol})\end{array}$} \\
\hline & G3 & $\operatorname{expt}^{a}$ & \\
\hline $\mathrm{H}_{2} / \mathrm{H}_{2} \mathrm{O}$ & -57.62 & $-57.8^{b}$ & 0.18 \\
\hline $\mathrm{H}_{2} \mathrm{O} / \mathrm{H}_{2} \mathrm{O}_{2}$ & 25.46 & 25.2 & 0.26 \\
\hline $\mathrm{HO}^{-} / \mathrm{HO}_{2}^{-}$ & 11.00 & $10.6^{b}$ & 0.40 \\
\hline $\mathrm{CH}_{4} / \mathrm{CH}_{3} \mathrm{OH}$ & -30.57 & -30.1 & 0.47 \\
\hline $\mathrm{C}_{2} \mathrm{H}_{4} / \mathrm{C}_{2} \mathrm{H}_{4} \mathrm{O}$ & -25.57 & -25.1 & 0.47 \\
\hline $\mathrm{MeCHO} / \mathrm{MeCO}_{2} \mathrm{H}$ & -64.05 & -63.6 & 0.45 \\
\hline${ }^{t} \mathrm{BuOH} /{ }^{t} \mathrm{BuO}_{2} \mathrm{H}$ & 16.79 & 15.9 & 0.89 \\
\hline $\mathrm{CO} / \mathrm{CO}_{2}$ & -69.01 & -67.6 & 1.41 \\
\hline $\mathrm{N}_{2} / \mathrm{N}_{2} \mathrm{O}$ & 18.68 & 19.6 & 0.92 \\
\hline $\mathrm{NO}_{2}^{-} / \mathrm{NO}_{3}{ }^{-}$ & -30.22 & $-29.0^{b}$ & 1.22 \\
\hline $\mathrm{Me}_{2} \mathrm{~S} / \mathrm{Me}_{2} \mathrm{SO}$ & -26.47 & -27.1 & 0.63 \\
\hline $\mathrm{Me}_{2} \mathrm{SO} / \mathrm{Me}_{2} \mathrm{SO}_{2}$ & -53.59 & -52.7 & 0.89 \\
\hline$(\mathrm{MeO})_{2} \mathrm{SO} /(\mathrm{MeO})_{2} \mathrm{SO}_{2}$ & -49.72 & -48.4 & 1.32 \\
\hline $\mathrm{MeONO} / \mathrm{MeONO}_{2}$ & -12.86 & -13.3 & 0.44 \\
\hline
\end{tabular}

${ }^{a}$ Source: ref 5 unless otherwise noted. ${ }^{b}$ Estimated from the experimental enthalpies of formation of the reactants and products given in the NIST Chemistry WebBook, Standard Reference Data Program.

free energies in the gas phase at $1 \mathrm{~atm}$ and $298.15 \mathrm{~K}$. Two basis sets were used for all the DFT and HF calculations: 6-31G(d) and cc-pVTZ. Solvent effects were initially evaluated with the Polarizable Continuum Model $\left(\mathrm{PCM}^{25}\right)$ for water at the B3LYP/ $6-31++\mathrm{G}(2 \mathrm{~d}, 2 \mathrm{p})$ level and applied to the G3 derived free energies for oxygen atom transfer in the gas phase. The preference of the $6-31++\mathrm{G}(2 \mathrm{~d}, 2 \mathrm{p})$ basis set over the $6-31+\mathrm{G}-$ $(d, p)$ or $6-31 G(d)$ originated from the preliminary trials that showed that a larger basis set provides better results within a comparable computational time. Other PCM variants, ${ }^{26}$ such as CPCM, IEFPCM, and COSMO/RS, were tested and no significant change in the calculated free energy of solvation was observed when the Gaussian98 was used with the default cavity model, i.e., UAHF. Additionally, different solute cavity models (UAKS, PAULING, and BONDI) were tested with the CPCM at both HF and B3LYP levels of theory employing the Gaussian03 package.

\section{Results and Discussion}

3.1. G3 Theory for Oxygen Atom Transfer Enthalpies. To establish a reference for accurate calculations, the G3 method was initially used to calculate the enthalpies for the gas-phase oxygen atom transfer reactions of interest. The test set consisted of $14 \mathrm{X} / \mathrm{XO}$ couples whose size was amenable to G3 calculations. The enthalpies of reaction were calculated at $298.15 \mathrm{~K}$ and then compared to experimental values reported in the literature..$^{5}$ The results (Table 1) showed that the average unsigned error (AUE) from experiment for the G3 method is $0.7 \mathrm{kcal} / \mathrm{mol}$. Only three reactions display an unsigned error higher than $1 \mathrm{kcal} / \mathrm{mol}$, which is within the G3 accuracy limit. ${ }^{10}$ The overall results show that the G3 method can be used as a reference when experimental data are not available or possess a large degree of uncertainty

3.2. DFT, HF, AM1, and PM3 Calculations of Oxygen Atom Transfer Enthalpies. The results of the calculated oxygen transfer enthalpies for the same test set of 14 reactions with DFT, HF, and semiempirical methods displayed substantial deviations (AUE varied from 10.35 to $24.02 \mathrm{kcal} / \mathrm{mol}$ ) from experiment (Table 2). Comparing the four selected functionals, both B3LYP and BLYP performed poorly, but better than BP86 and SVWN, with significant deviations from the experiment (AUE was greater than $10 \mathrm{kcal} / \mathrm{mol}$ for all functionals). The 6-31G(d) and cc-pVTZ basis sets provided similar accuracy for oxygen atom transfer enthalpies, and therefore, in the QM/QM
TABLE 2: Average Unsigned Errors (AUE) in Oxygen Atom Transfer Enthalpies for DFT, HF, and Semiempirical Methods

\begin{tabular}{lcc}
\hline method & basis set & AUE $(\mathrm{kcal} / \mathrm{mol})$ \\
\hline B3LYP & 6-31G(d) & 14.74 \\
& cc-pVTZ & 13.63 \\
BLYP & 6-31G(d) & 15.21 \\
& cc-pVTZ & 13.78 \\
BP86 & 6-31G(d) & 16.35 \\
& cc-pVTZ & 15.17 \\
SVWN & 6-31G(d) & 25.69 \\
& cc-pVTZ & 25.72 \\
HF & 6-31G(d) & 11.15 \\
& cc-pVTZ & 10.35 \\
AM1 & & 23.20 \\
PM3 & & 24.02
\end{tabular}

TABLE 3: Comparison of Calculated Reaction Enthalpies with Use of Different QM/QM Hybrid Schemes ${ }^{a}$

\begin{tabular}{|c|c|c|c|c|}
\hline \multirow[b]{2}{*}{$\mathrm{X} / \mathrm{XO}$} & \multicolumn{4}{|c|}{$\Delta H_{\mathrm{OAT}}(\mathrm{kcal} / \mathrm{mol})$} \\
\hline & G3/B3LYP ${ }^{a}$ & G3/AM1 & G3/PM3 & $\operatorname{exptl}^{b}$ \\
\hline $\mathrm{MeCHO} / \mathrm{MeCO}_{2} \mathrm{H}$ & -62.84 & -61.16 & -62.11 & -63.6 \\
\hline${ }^{t} \mathrm{BuOH} /{ }^{t} \mathrm{BuO}_{2} \mathrm{H}$ & 18.53 & 18.86 & 22.26 & 15.9 \\
\hline $\mathrm{Me}_{2} \mathrm{~S} / \mathrm{Me}_{2} \mathrm{SO}$ & -24.82 & -7.61 & -9.51 & -27.1 \\
\hline $\mathrm{Me}_{2} \mathrm{SO} / \mathrm{Me}_{2} \mathrm{SO}_{2}$ & -52.25 & -47.94 & -41.06 & -52.7 \\
\hline $\mathrm{MeONO} / \mathrm{MeONO}_{2}$ & -14.71 & -14.70 & -14.30 & -13.3 \\
\hline $\mathrm{Me}_{3} \mathrm{P} / \mathrm{Me}_{3} \mathrm{PO}$ & -75.11 & -55.82 & -36.70 & -79.7 \\
\hline $\mathrm{Ph}_{3} \mathrm{P} / \mathrm{Ph}_{3} \mathrm{PO}$ & -74.01 & -52.86 & -39.72 & -73.8 \\
\hline $\mathrm{MeOH} / \mathrm{MeO} 2 \mathrm{H}$ & 19.39 & 26.25 & 26.55 & 16.7 \\
\hline $\mathrm{EtOH} / \mathrm{EtO}_{2} \mathrm{H}$ & 19.40 & 25.37 & 26.09 & $6.2^{c}$ \\
\hline${ }^{n} \mathrm{PrOH} /{ }^{n} \mathrm{PrO}_{2} \mathrm{H}$ & 19.48 & 25.37 & 26.02 & 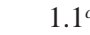 \\
\hline${ }^{i} \mathrm{PrOH} /{ }^{2} \mathrm{PrO} 2 \mathrm{H}$ & 18.05 & 19.54 & 21.78 & $18.1^{\mathrm{c}} \mathrm{r}-\mathrm{m}-\mathrm{x}$ \\
\hline${ }^{t} \mathrm{BuOH} /{ }^{t} \mathrm{BuO}{ }_{2} \mathrm{H}$ & 18.53 & 18.86 & 22.26 & $18.6^{\circ}$ \\
\hline
\end{tabular}

${ }^{a}$ The $6-31 \mathrm{G}(\mathrm{d})$ basis set was employed. ${ }^{b}$ Source: ref 5 unless otherwise noted. ${ }^{c}$ Estimated from the experimental enthalpies of formation of the reactants and products given in the NIST Chemistry WebBook, Standard Reference Data Program.

subsequent calculations we have used the more compact 6-31G(d) basis set to conserve computational resources. The smallest errors were obtained unexpectedly by using the HF theory, but in this case the results probably reflect an error cancellation from lack of electron correlation and limited basis sets. On the other hand, the largest errors (AUE was greater than $20 \mathrm{kcal} /$ mol) were produced as expected by the SVWN, PM3, and AM1 methods.

3.3. QM/QM Calculation of Oxygen Atom Transfer Enthalpies. Since a goal of this research is to obtain accurate results for larger chemical systems and even DFT methods performed unconvincingly, we tested the ability of a two-layered composite method, based on the $\mathrm{ONIOM}^{27}$ model, using G3 as the higher level method and different lower level methods (LL), such as B3LYP/6-31G(d), AM1, and PM3. For the truncated models (M) the methyl, $n$-alkyl, and aryl groups were replaced with hydrogen atoms and enthalpies were calculated at both levels of theory (G3 and lower level method), while for the actual molecules $(\mathrm{R})$ enthalpies were calculated only at the lower level of theory. Finally, the enthalpies of formation were estimated (eq 2) and implemented into the oxygen transfer enthalpies.

$$
\Delta H_{\mathrm{f}}^{0}=\Delta H_{\mathrm{f}}^{0}(\mathrm{M}-\mathrm{G} 3)+\Delta H_{\mathrm{f}}^{0}(\mathrm{R}-\mathrm{LL})-\Delta H_{\mathrm{f}}^{0}(\mathrm{M}-\mathrm{LL})
$$

The results (Table 3) show a good agreement with the experimental values only for the G3/B3LYP composite scheme and only when the methyl/aryl groups are replaced with hydrogen atoms for the model $(\mathrm{AUE}=1.39 \mathrm{kcal} / \mathrm{mol})$. For the systems with an ethyl or $n$-propyl group $\left(\mathrm{EtOH} / \mathrm{EtO}_{2} \mathrm{H},{ }^{n} \mathrm{PrOH} /\right.$ 
TABLE 4: Calculated OAT Free Energies in the Gas Phase and Aqueous Solution with Use of the PCM

\begin{tabular}{|c|c|c|c|}
\hline \multirow[b]{2}{*}{$\mathrm{X} / \mathrm{XO}$} & \multicolumn{3}{|c|}{$\Delta G_{\mathrm{OAT}}(\mathrm{kcal} / \mathrm{mol})$} \\
\hline & gas-phase (G3) & aqueous $^{a}$ & $\operatorname{exptl}_{(\mathrm{aq})} b$ \\
\hline $\mathrm{HO}^{-} / \mathrm{HO}_{2}^{-}$ & 14.49 & 38.08 & 21.48 \\
\hline $\mathrm{H}_{2} \mathrm{O} / \mathrm{H}_{2} \mathrm{O}_{2}$ & 29.60 & 24.10 & 24.64 \\
\hline $\mathrm{HCHO} / \mathrm{HCO}_{2} \mathrm{H}$ & -59.01 & -63.47 & -54.09 \\
\hline $\mathrm{HCO}_{2}^{-} / \mathrm{HCO}_{3}^{-}$ & -56.58 & -53.28 & -56.42 \\
\hline $\mathrm{NO}_{2}^{-} / \mathrm{NO}_{3}^{-}$ & -24.62 & -20.11 & -17.76 \\
\hline $\mathrm{HNO}_{2} / \mathrm{HNO}_{3}$ & -8.39 & -9.15 & -13.31 \\
\hline $\mathrm{NH}_{3} / \mathrm{NH}_{2} \mathrm{OH}$ & 4.31 & 2.26 & 11.95 \\
\hline $\mathrm{CN}^{-} / \mathrm{OCN}^{-}$ & -64.26 & -57.12 & -63.26 \\
\hline $\mathrm{SO}_{3}{ }^{2-} / \mathrm{SO}_{4}{ }^{2-}$ & -72.29 & -83.82 & -61.67 \\
\hline $\mathrm{HSO}_{3}{ }^{-} / \mathrm{HSO}_{4}{ }^{-}$ & -54.77 & -65.37 & -54.54 \\
\hline $\mathrm{H}_{2} \mathrm{SO}_{3} / \mathrm{H}_{2} \mathrm{SO}_{4}$ & -41.02 & -54.54 & -49.41 \\
\hline $\mathrm{Cl}^{-} / \mathrm{ClO}^{-}$ & 28.67 & 33.70 & 22.53 \\
\hline $\mathrm{ClO}^{-} / \mathrm{ClO}_{2}^{-}$ & 6.56 & 9.78 & 12.91 \\
\hline $\mathrm{ClO}_{2}{ }^{-} / \mathrm{ClO}_{3}^{-}$ & -18.51 & -12.57 & -4.90 \\
\hline $\mathrm{ClO}_{3}{ }^{-} / \mathrm{ClO}_{4}^{-}$ & -5.15 & -0.63 & -1.27 \\
\hline $\mathrm{HCl} / \mathrm{HClO}$ & 7.67 & 2.69 & 12.23 \\
\hline $\mathrm{HClO} / \mathrm{HClO}_{2}$ & 28.03 & 26.45 & 20.51 \\
\hline $\mathrm{HClO}_{2} / \mathrm{HClO}_{3}$ & 0.66 & 0.87 & -2.20 \\
\hline $\mathrm{HClO}_{3} / \mathrm{HClO}_{4}$ & 9.98 & 9.37 & -1.27 \\
\hline $\mathrm{AUE}^{c}$ & 5.9 & 7.5 & \\
\hline
\end{tabular}

${ }^{a}$ The solvent correction for water was calculated at the B3LYP/6$31++\mathrm{G}(2 \mathrm{~d}, 2 \mathrm{p})$ level, using the PCM aquation with the default UAHF cavity and applied to the G3 free energy in the gas phase. ${ }^{b}$ Estimated from experimental free energies of formation of products and reactants given in: Standard Potentials in Aqueous Solution; Bard, A. J., Parsons, R., Jordan, J., Eds.; Marcel Dekker, New York, 1985. ${ }^{c}$ AUE = average unsigned error.

${ }^{n} \mathrm{PrO}_{2} \mathrm{H}$ in Table 3), the AUE increased significantly to 13.2 and $18.4 \mathrm{kcal} / \mathrm{mol}$, respectively. The G3/AM1 and G3/PM3 composite methods gave even higher theory-experiment deviations, predicting much more endothermic enthalpies, especially for systems with second row main group elements.

3.4. Calculation of Oxygen Atom Transfer Free Energies in Aqueous Solution. Many important industrial and biological oxygen atom transfer reactions take place in solution. Furthermore, some of the largest theory-experiment deviations were seen for ionic systems, for which the experimental thermodynamics were measured in the aqueous phase. Hence, in this section the influence of bulk solvent effects on OAT free energies is analyzed. As the PCM solvation corrections could not be determined at the G3 level of theory, aquation corrections for 19 neutral and anionic systems were calculated at the B3LYP/6-31++G(2d,2p) level of theory and applied to gasphase G3 free energies. The default UAHF cavity model (Gaussian98) is used and the theoretical results are shown in Table 4. The AUE for oxygen atom transfer free energies in aqueous solution is $7.5 \mathrm{kcal} / \mathrm{mol}$, which is surprisingly ca. 1.5 $\mathrm{kcal} / \mathrm{mol}$ greater than the AUE calculated without considering solvent effects. The preceding conclusion applies to both neutral and ionic systems and we attribute this result to an inappropriate cavity size in the PCM calculation.

Takano and Houk have previously shown ${ }^{28}$ that HF-CPCM calculations with cavities determined with use of UAKS radii produce reliable results for the aqueous free energy corrections. Moreover, they observed that CPCM is faster when large molecules are involved, and more accurate than PCM. Other PCM variants, such as IEFPCM and COSMO/RS, were tested with UAHF cavities (Gaussian98) and no significant change in the calculated free energy of solvation was observed. On the basis of these findings, we investigate herein the effectiveness of the CPCM with UAKS, PAULING, and BONDI solute cavities over the OAT reactions in aqueous environment by
TABLE 5: Comparison of the Unsigned Errors (kcal/mol) for the OAT Free Energies in Aqueous Solution with Use of Three Different Cavities within $\mathrm{CPCM}^{a}$

\begin{tabular}{|c|c|c|c|c|c|c|}
\hline \multirow[b]{2}{*}{$\mathrm{X} / \mathrm{XO}$} & \multicolumn{3}{|c|}{$\mathrm{HF} / 6-31++\mathrm{G}(2 \mathrm{~d}, 2 \mathrm{p})$} & \multicolumn{3}{|c|}{$\mathrm{B} 3 \mathrm{LYP} / 6-31++\mathrm{G}(2 \mathrm{~d}, 2 \mathrm{p})$} \\
\hline & UAKS & PAULING & BONDI & UAKS & PAULING & BONDI \\
\hline $\mathrm{HO}^{-} / \mathrm{HO}_{2}^{-}$ & 11.53 & 2.55 & 1.65 & 8.15 & 0.11 & 0.74 \\
\hline $\mathrm{H}_{2} \mathrm{O} / \mathrm{H}_{2} \mathrm{O}_{2}$ & 1.41 & 4.38 & 4.52 & 0.86 & 4.59 & 4.74 \\
\hline $\mathrm{HCHO} / \mathrm{HCO}_{2} \mathrm{H}$ & 11.54 & 0.73 & 4.29 & 11.36 & 3.59 & 6.07 \\
\hline $\mathrm{HCO}_{2}{ }^{-} / \mathrm{HCO}_{3}{ }^{-}$ & 0.24 & 2.12 & 1.86 & 1.05 & 0.56 & 0.62 \\
\hline $\mathrm{NO}_{2}^{-} / \mathrm{NO}_{3}{ }^{-}$ & 4.49 & 2.00 & 1.90 & 5.04 & 3.15 & 2.88 \\
\hline $\mathrm{HNO}_{2} / \mathrm{HNO}_{3}$ & 0.47 & 2.83 & 1.98 & 1.44 & 0.48 & 0.17 \\
\hline $\mathrm{NH}_{3} / \mathrm{NH}_{2} \mathrm{OH}$ & 12.50 & 10.69 & 10.17 & 11.99 & 9.97 & 9.62 \\
\hline $\mathrm{CN}^{-} / \mathrm{OCN}^{-}$ & 1.05 & 0.84 & 0.65 & 1.59 & 0.33 & 0.98 \\
\hline $\mathrm{SO}_{3}{ }^{2-} / \mathrm{SO}_{4}{ }^{2-}$ & 19.47 & 2.81 & 1.76 & 19.23 & 0.05 & 0.61 \\
\hline $\mathrm{HSO}_{3}{ }^{-} / \mathrm{HSO}_{4}{ }^{-}$ & 12.56 & 1.22 & 1.02 & 11.68 & 0.16 & 0.09 \\
\hline $\mathrm{H}_{2} \mathrm{SO}_{3} / \mathrm{H}_{2} \mathrm{SO}_{4}$ & 8.10 & 2.62 & 3.49 & 6.61 & 3.19 & 4.03 \\
\hline $\mathrm{Cl}^{-} / \mathrm{ClO}^{-}$ & 5.66 & 1.55 & 4.88 & 4.92 & 1.70 & 4.49 \\
\hline $\mathrm{ClO}^{-} / \mathrm{ClO}_{2}^{-}$ & 2.06 & 3.29 & 3.20 & 0.60 & 0.63 & 0.95 \\
\hline $\mathrm{ClO}_{2}{ }^{-} / \mathrm{ClO}_{3}{ }^{-}$ & 8.98 & 8.16 & 8.95 & 8.71 & 7.34 & 8.09 \\
\hline $\mathrm{ClO}_{3}^{-} / \mathrm{ClO}_{4}^{-}$ & 2.76 & 5.82 & 5.61 & 1.36 & 3.48 & 3.48 \\
\hline $\mathrm{HCl} / \mathrm{HClO}$ & 10.48 & 7.76 & 7.54 & 10.07 & 7.24 & 7.11 \\
\hline $\mathrm{HClO} / \mathrm{HClO}_{2}$ & 2.00 & 2.40 & 1.85 & 3.98 & 1.14 & 1.27 \\
\hline $\mathrm{HClO}_{2} / \mathrm{HClO}_{3}$ & 4.40 & 4.74 & 4.63 & 4.26 & 4.70 & 4.73 \\
\hline $\mathrm{HClO}_{3} / \mathrm{HClO}_{4}$ & 9.66 & 12.18 & 13.34 & 9.47 & 11.30 & 12.54 \\
\hline $\mathrm{AUE}^{b}$ & 6.81 & 4.14 & 4.38 & 6.44 & 3.35 & 3.85 \\
\hline median & 5.66 & 2.81 & 3.49 & 5.04 & 3.15 & 3.48 \\
\hline
\end{tabular}

${ }^{a}$ The solvent correction for water was applied to the G3 free energy in the gas phase. ${ }^{b}$ AUE $=$ average unsigned error.

using both HF and B3LYP methods in conjunction with the $6-31++G(2 d, 2 p)$ basis set. The unsigned errors obtained with Gaussian03 with the different recipes for radii (and hence the solute volumes derived from them) are compared in Table 5. Our results indicate that the B3LYP functional yields marginally better results than $\mathrm{HF}$ (by $\sim 0.5 \mathrm{kcal} / \mathrm{mol}$ ). Furthermore, the cavities calculated with PAULING radii provide the solvent corrected free energies that are the closest to reported experimental data (AUE is 3.4 and $4.1 \mathrm{kcal} / \mathrm{mol}$ for the B3LYP and $\mathrm{HF}$, respectively). The UAKS cavities give considerable deviations from the experiment. The AUEs for CPCM/UAKScorrected free energies (at both B3LYP/6-31++G(2d,2p) and $\mathrm{HF} / 6-31++\mathrm{G}(2 \mathrm{~d}, 2 \mathrm{p})$ levels of theory) are even greater than the $5.9 \mathrm{kcal} / \mathrm{mol}$ gas-phase error (cf. Tables 4 and 5). The BONDI cavity approximations are comparable to PAULING results, but slightly inferior (AUE is 3.9 and $4.4 \mathrm{kcal} / \mathrm{mol}$ for the B3LYP and $\mathrm{HF}$, respectively). This error distribution is due mainly to a better estimation of the solvation free energy with PAULING cavities for the sulfur-containing $\mathrm{X} / \mathrm{XO}$ couples (anions and neutrals), $\mathrm{HO}^{-} / \mathrm{HO}_{2}{ }^{-}$, and $\mathrm{HCHO} / \mathrm{HCO}_{2} \mathrm{H}$. When these five OAT couples are discarded, the AUEs for all three cavity models are similar.

\section{Conclusions}

The performance of four DFT methods (SVWN, BP86, BLYP, and B3LYP) was tested for the OAT enthalpies and found to be inadequate when combined with both compact Pople-style $(6-31 G(d))$ as well as larger correlation consistent (cc-pVTZ) basis sets. The hybrid B3LYP and pure BLYP functionals performed very similarly. Thus, it appears that parametrization of the HF exchange in B3LYP may not improve the accuracy for thermochemistry prediction. In a recent publication, ${ }^{29}$ Grimme reported similarly large errors in thermochemistry for the most popular DFT methods even with very large (i.e., QZV3P) basis sets on a test set that included charged, halogenated, strained, hypervalent, and large unsaturated species. Grimme substantiated the importance of a larger HF exchange fraction in hybrid functionals for better enthalpy estimation. 
Since the G3 theory accurately calculated the reaction enthalpies for the test set (inorganic and organic systems, charged and neutral species, first and second row atom containing molecules), it was further evaluated as the higher level in an ONIOM-based scheme to study larger oxidants. It has previously been shown that the G3B3 variation of G3 theory coupled with the B3LYP/6-31G(d) method gives good results for bond dissociation enthalpies of $\mathrm{C}-\mathrm{H}$ and $\mathrm{N}-\mathrm{H}$ bonds. ${ }^{30}$ Partly, this is valid also for the OAT reaction enthalpies. Our results show that the composite G3:B3LYP scheme with compact basis set gives better results than the use of G3 in combination with the semiempirical methods, AM1 and PM3. However, when the outer layer consists of an $n$-alkyl group it produces large deviations from experiment. These deviations could be due to the errors of the extrapolation procedure between the higher level and lower level theories.

Solvent effects were calculated at the B3LYP/6-31++G$(2 d, 2 p)$ and $H F / 6-31++G(2 d, 2 p)$ levels of theory with three radii schemes for calculating cavities-UAKS, PAULING, and BONDI-using the CPCM approach. The thermochemical results showed significant differences between the tested solute cavities. The best agreement with experimental energetics for OAT was obtained for the B3LYP method and PAULING solute cavities, contrasting the data ${ }^{28}$ reported by Takano and Houk that showed better results with HF and UAKS cavities. Besides the fact that we tested distinctive chemical systems, another possible explanation for this discrepancy is that we used the G3 composite method for determining the energetics of the gasphase OAT reactions while the Takano and Houk method was B3LYP/6-31+G(d). Additionally, the different radii gave similar results when a few outliers were excluded. Regardless of the differences, the overall conclusion in light of the present and previous $^{28}$ results is that when solvent effects are considered, the choice of the radii used to calculate the solute cavity is essential, and indeed seemingly more consequential than the effect of the level of theory and basis set.

In sum, the DFT methods performed inadequately for OAT thermochemistry predictions and thus caution must be used even with the popular B3LYP functional, especially for large and charged species that include elements beyond the first row. Significant errors in OAT thermochemistry were seen even for the reasonably large cc-pVTZ basis set in conjunction with DFT. Post-Hartree-Fock methods in the form of the G3 composite method are required to approach chemical accuracy for this family of important chemical transformations. The CPCM corrections for solvent effects at the B3LYP level can significantly improve gas-phase calculated free energies vis-à-vis experimental data, but care must be taken in the choice of method for calculating the solute cavity. However, the choice of gas phase method is as important as the cavity model. This research indicates that bulk solvent effects only slightly modify intrinsic oxygen atom transfer ability in solution, and therefore suggests that energetic "ladders" of oxygen atom transfer ability developed primarily on the basis of gas-phase free energies will have utility even for the more chemically and industrially relevant solvent phase.

Acknowledgment. The authors acknowledge the Office of Basic Energy Sciences, U.S. Department of Energy for support of this research through grant DOE-FG02-97ER14811. A portion of the calculations was performed on the UNT computational chemistry resource, for which the authors acknowledge the NSF for support through grant CHE-0342824. C.W. and R.R.C. were NSF-REU scholars (grant CHE-0243795) at the University of North Texas.

Supporting Information Available: Calculated oxygen atom transfer enthalpies using the G3, DFT, HF, AM1, and PM3 methods for the $14 \mathrm{X} / \mathrm{XO}$ couples, including their associated errors, are shown in Tables S1 and S2; the OAT free energies in aqueous solution calculated by using the CPCM with UAKS, PAULING, and BONDI cavities are shown in Table S3. This material is available free of charge via the Internet at http:// pubs.acs.org.

\section{References and Notes}

(1) Stassinopoulos, A.; Mukerjee, S.; Caradonna, J. P. Adv. Chem. Ser. 1995, 246,83 .

(2) Espenson, J. H. Coord. Chem. Rev. 2005, 249, 329.

(3) Jacobi, B. G.; Laitar, D. S.; Pu, L.; Wargocki, M. F.; DiPasquale, A. G.; Fortner, K. C.; Schuck, S. M.; Brown, S. N. Inorg. Chem. 2002, 41, 4815 .

(4) Holm, R. H. Chem. Rev. 1987, 87, 1401.

(5) Holm, R. H.; Donahue, J. P. Polyhedron 1993, 12, 571.

(6) Koch, W., Holthausen, M. C. A Chemist's Guide to Density Functional Theory; Wiley-VCH: Weinheim, Germany, 2000.

(7) Curtiss, L. A.; Jones, C.; Trucks, G. W.; Raghavachari, K.; Pople, J. A. J. Chem. Phys. 1990, 93, 2537.

(8) Pople, J. A.; Head-Gordon, M.; Fox, D. J.; Raghavachari, K.; Curtiss, L. A. J. Chem. Phys. 1989, 90, 5622.

(9) Curtiss, L. A.; Raghavachari, K.; Trucks, G. W.; Pople, J. A. J. Chem. Phys. 1991, 94, 7221.

(10) Curtiss, L. A.; Raghavachari, K.; Redfern, P. C.; Rassolov, V.; Pople, J. A. J. Chem. Phys. 1998, 109, 7764.

(11) Bartlett, R. J.; Stanton, J. F. In Reviews in Computational Chemistry; Lipkowitz, K. B., Boyd, D. B., Eds.; VCH: New York, 1994; Vol. 5.

(12) Chemical Abstracts Service (CAS) for most cited articles as pertains to journals covered by CAS, and under the subject heading of chemistry (http://www.cas.org/spotlight/bchem.html). The B3LYP articles occupy the top spots in the most cited articles list for the years 1999 through 2004.

(13) Becke, A. D. J. Chem. Phys. 1993, 98, 1372.

(14) Lee, C.; Yang, W.; Parr, R. G. Phys. Rev. 1988, B37, 785.

(15) Curtiss, L. A.; Raghavachari, K.; Redfern, P. C.; Rassolov, V.; Pople, J. A. J. Chem. Phys. 1997, 106, 1063.

(16) Roothan, C. C. J. Rev. Mod. Phys. 1951, 23, 69.

(17) Dewar, M. J. S.; Zoebisch, E. G.; Healy, E. F.; Stewart, J. J. P. J. Am. Chem. Soc. 1985, 107, 3902.

(18) Stewart, J. J. P. J. Comput. Chem. 1989, 10, 264.

(19) Wavefunction Inc., Irvine, CA, 1999.

(20) (a) Frisch, M. J.; et al. Gaussian 98, Revision A.11.3; Gaussian Inc.: Pittsburgh, PA, 2002. (b) Frisch, M. J.; et al. Gaussian 03, Revision C.02; Gaussian Inc.: Wallingford, CT, 2004.

(21) Kohn, W.; Sham, L. Phys. Rev. 1965, A140, 1133.

(22) Vosko, S. H.; Wilk, L.; Nusair, M. Can. J. Phys. 1980, 58, 1200.

(23) Becke, A. D. Phys. Rev. 1998, A38, 3098.

(24) Perdew, J. P. Phys. Rev. 1986, B33, 8822

(25) Tomasi, J.; Mennucci, B.; Cammi, R. Chem. Rev. 2005, 105, 2999.

(26) (a) Barone, V.; Cossi, M. J. Phys. Chem. 1998, A102, 1995. (b) Cossi, M.; Rega, N.; Scalmani, G.; Barone, V. J. Comput. Chem. 2003, 24, 669. (c) Chipman, D. M. J. Chem. Phys. 2000, 112, 5558. (d) Klamt, A.; Schurmann, G. J. Chem. Soc., Perkin Trans. 2 1993, 799. (e) Andzelm, J.; Kolmel, C.; Klamt, A. J. Chem. Phys. 1995, 103, 9312.

(27) Maseras, F.; Morokuma, K. J. Comput. Chem. 1995, 16, 1170.

(28) Takano, Y.; Houk, K. N. J. Chem. Theory Comput. 2005, 1, 70.

(29) Grimme, S. J. Phys. Chem. 2005, A109, 3067.

(30) Li, M. J.; Liu, L.; Fu, Y.; Guo, Q. X. J. Phys. Chem. 2005, B109, 13818. 